\title{
Genus Metacosma Kuznetsov (Lepidoptera: Tortricidae) in China, with description of a new species
}

\author{
Aihuan Zhang \\ Zhang, A. 2012: Genus Metacosma Kuznetsov (Lepidoptera: Tortricidae) in \\ China, with description of a new species. - Entomol. Fennica 23: 1-3. \\ Metacosma bifurcata sp. n. is described from China. Photographs of the adult \\ and the genital structures are provided. The female of Metacosma is firstly found \\ in China. \\ A. Zhang, Beijing Key Laboratory for Agricultural Application and New Tech- \\ nique, College of Plant Science and Technology, Beijing University of Agricul- \\ ture, Beijing 102206, P. R. China; E-mail: zhangaihuan@126.com
}

Received 27 December 2011, accepted 24 January 2012

\section{Introduction}

Metacosma is a small genus of Tortricidae, proposed by Kuznetsov (1985). It includes four species prior to this study. Metacosma impolitana Kuznetsov, 1985 is distributed in Russia, M. miratorana Kuznetsov, 1988 in North Vietnam, $M$. triangulata Zhang \& Li, 2009 and M. trapezia Zhang \& Li, 2009 in China.

In the present paper Metacosma bifurcata $\mathbf{s p .}$ n. is described as new to the science. The species is closely related with $M$. triangulata Zhang \& Li.

\section{Material and methods}

The study is based on examination of specimens collected by light traps from forests and mountains in Mt. Fengyang, Zhejiang Province, China. Wing pattern morphological terminology follows Brown and Powell (1991) as refined by Baixeras (2002). Genitalia dissection method follows Li (2002). All the specimens examined are deposited in the Insect Collection, College of Life Sciences, Nankai University, Tianjin, China.

\section{Description of Metacosma bifurcata Zhang sp. n. (Fig. 1)}

Type material. Holotype $\widehat{\partial}$, China: Longquan County $\left(28.04^{\circ} \mathrm{N}, 119.08^{\circ} \mathrm{E}\right)$, Mt. Fengyang, Lishui City, Zhejiang Province, alt. 1,470 m, 25.VII.2007, coll. Jin Qing, genitalia slide no. ZAH07007. Paratypes: $2 \hat{\jmath} \hat{\partial}, 1$, same data as holotype.

Diagnosis. The species is similar to M. triangulata Zhang \& Li, 2009, but can be distinguished by the short, slightly broad and posteriorly bifurcated uncus, the relatively zonary socius drooping and the cucullus with eight stout ventral spines. In the latter species, the uncus is relatively large, nearly triangular, the minute socius is mastoid and the cucullus has six stout ventral spines. The female genitalia resemble those of M. impolitana Kuznetsov, 1985 and can be separated by the shape of sterigma and $7^{\text {th }}$ sternite. In $M$. bifurcata $\mathbf{s p .} \mathbf{n}$. sterigma is elongate semi-elliptic and $7^{\text {th }}$ sternite is sclerotized into a broad semicircular plate. In M. impolitana sterigma is rectangular and $7^{\text {th }}$ sternite is sclerotized into a subtriangular plate. 

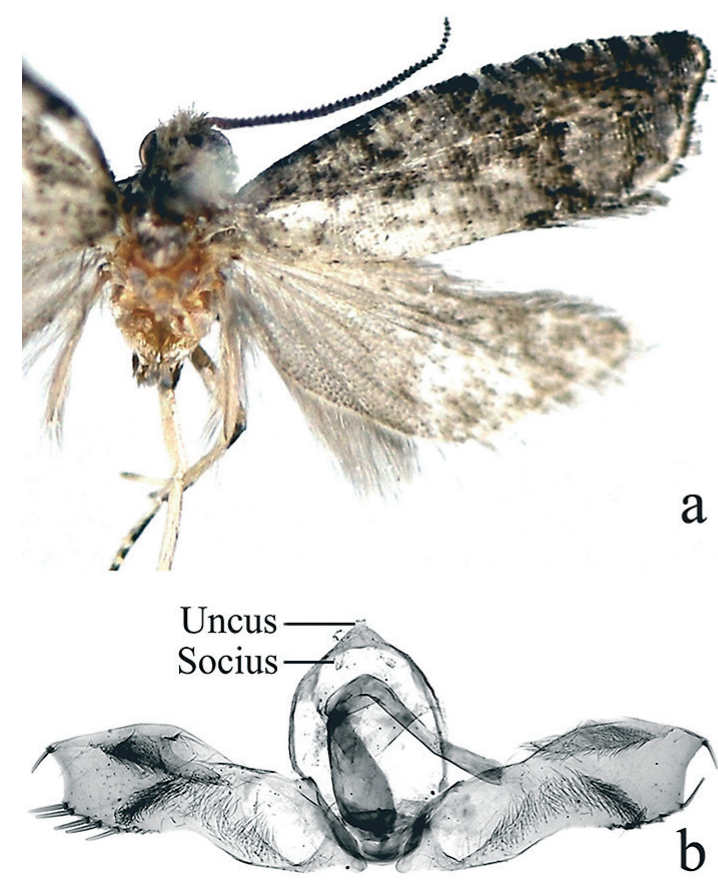

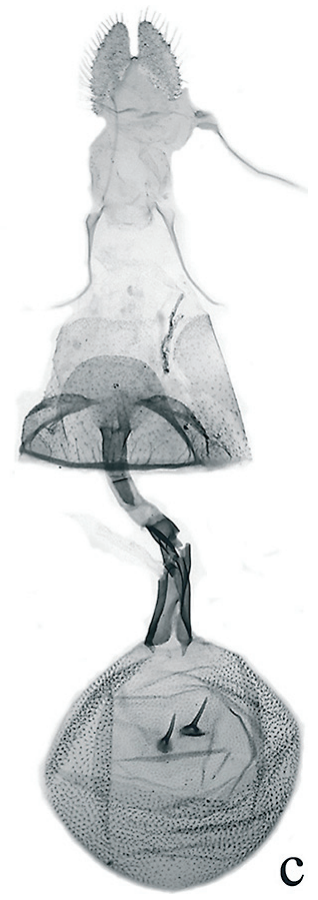

Fig. 1. Metacosma bifurcata Zhang sp. $\mathbf{n}$. - a. Adult. - b. Male genitalia, slide no. ZAH07007. - c. Female genitalia, slide no. ZAH07009.
Description. Adult (Fig. 1a).

Head. Vertex with dark brown scales, frons white. Antenna dark brown. Labial palpus brown, third segment slightly drooping.

Thorax. Thorax and tegula brown. Legs light brown, tarsi with white rings. Forewing length 4.5-5.0 mm; upside ground color dark grey; basal fascia and subbasal fascia forming a basal patch, extending from costal $1 / 4$ to $1 / 3$ of dorsum, protrudent in middle on outer margin; median fascia extending from costal $1 / 2$ to $2 / 3$ of dorsum, protrudent in middle; postmedian fascia parallel to median fascia, extending from distal $1 / 3$ of costa to tornus; ocellus nearly round, with silvery scales; termen dark grey; costa with nine pairs of white strigulae; strigulae 1-4 between base and the point where Sc meets costa; strigulae 5 and 6 between $\mathrm{Sc}$ and $\mathrm{R}_{1}$ points, each containing one short stria, just like one pair of strigulae; distal three pairs clearer than others, distributed between pairs of veins $\mathrm{R}_{1}-\mathrm{R}_{2}, \mathrm{R}_{2}-\mathrm{R}_{3}, \mathrm{R}_{3}-\mathrm{R}_{4}$ respectively; cilia dark grey. Upside hind wing and cilia grey.

Abdomen. Abdomen light brown concolor with thorax.

Male genitalia (Fig. 1b). Uncus short, slightly broad at base, haired and bifurcated, produced into two minute processes posteriorly. Socius somewhat zonary, drooping, armed with long hairs. Valva without basal process; neck slightly narrower than base; sacculus hairy; with weak angle; cuculli symmetrical, with a stout dorsoapical spine and eight ventral ones (some lost but can be seen from inserted hole); a bristled band extending from beyond middle extending to costa. Aedeagus slightly longer than valva, broad at base, gradually narrowed to middle, then curved at about middle; cornuti deciduous.

Female genitalia (Fig. 1c). Papilla analis somewhat triangular, setose. Anterior apophysis slightly shorter than posterior apophysis. Ostium large, infundibular. Sterigma elongate semi-elliptic, situated bilaterally. $7^{\text {th }}$ sternite sclerotized into a broad semicircular plate situated behind ostium. Ductus bursae slender, with a sclerotized band occupying anterior half, distally produced into two minute processes and extending into corpus bursae; colliculum located near base, narrowed distally, covered about $1 / 3$ of ductus bursae; ductus seminalis originated from distal $1 / 3$ of ductus bursae. Corpus bursae rounded, spinulose except posterior end and area around signa; signa two, large and spinelike, with rounded sclerotized basal plate. 
Etymology. The specific name is derived from the Latin bifurcatus, referring to the shape of uncus.

\section{Discussion}

Metacosma is firstly reported by Kuznetsov (1985) with a Russian Far East species. Then Kuznetsov (1988) and Zhang and Li (2009) reported another three species from Vietnam and China. In the present paper, one new species is added and the female of Metacosma is recorded for the first time in China.

Metacosma is a small genus of Tortricidae including only five species to date. Each species is represented by few specimens. Three species are known in China but male and female specimens of only one species have been found. Moreover, there are only eight specimens of Metacosma found in China. Early stages and hostplants are unknown.

The autapomorphy of Metacosma is a bristled band extending from beyond middle reaching costa in the male genitalia, a condition not found in other genera of Eucosmini of Olethreutinae. This genus was originally compared with Spilonota Stephens based on the similarity of the female genitalia, especially in the structure of the $7^{\text {th }}$ sternite and its fusion with the ostium. The sterigma of Spilonota is fused with $7^{\text {th }}$ sternite and producing into a pair of subterminal lobes posteriorly. The Spilonota species are similar in the male genitalia but the depth between subterminal lobes in the female genitalia is the main character in distinguishing species. In Metacosma Kuznetsov, the male genitalia characters can be used to separate species. On the one hand, there are relatively many clear differences in uncus, socius and valva (e.g. the shape of uncus and socius, number and inserted position of stout spines); on the other hand, the female specimens are very few to date though there may be some valuable characters such as the shape of sterigma and $7^{\text {th }}$ sternite. Razowski (1989) mentioned the male genitalia remind those in Rhopobota Lederer, especially as concerned the shape of valva. Accordingly, he placed Metacosma near Rhopobota and Spilonota. But I consider there are no more characters to support the relations between Metacosma and Rhopobota. Another special character is reflected in venation. $\mathrm{M}_{3}$ and $\mathrm{Cu}_{1}$ are well separated in hindwing of Metacosma, while in most genera of Eucosmini $\mathrm{M}_{3}$ and $\mathrm{Cu}_{1}$ in hindwing are stalked.

In conclusion, Metacosma is an interesting and unique genus of Eucosmini of Olethreutinae. The character and function of a bristled band in the male genitalia deserves more attention. The confirmation of the taxonomic status of Metacosma lies on future studies on more specimens and species including early stages and hostplants.

Acknowledgments. I am grateful to Dr. Houhun Li (Nankai University, P. R. China) for checking specimens and detailed revisions. I also express my sincere thanks to Dr. Shuxia Wang (Nankai University, P. R. China) and the referees (Dr. J. Baixeras (Universitat de Valčncia, Spain) and an anonymous referee) for editorial comments and good suggestions on the manuscript. The research was supported by the National Natural Science Foundation of China (J0630963, 31101665), Beijing Nova Program (2008B23) and Beijing Natural Science Foundation (5123042).

\section{References}

Baixeras, J. 2002: An overview of genus-level taxonomic problems surrounding Argyroploce Hübner (Lepidoptera: Tortricidae), with description of a new species. - Annals of the Entomological Society of America 95: 422-431.

Brown, R. L. \& Powell, J. A. 1991: Description of a new species of Epiblema (Lepidoptera: Tortricidae: Olethreutinae) from coastal redwood forests in California with an analysis of the forewing pattern. - The PanPacific Entomologist 67: 107-114.

Kuznetsov, V. I. 1985: New representatives of the tribe Eucosmini (Lepidoptera, Tortricidae) of the USSR Asiatic part. - Vestnik Zoologii 1: 3-11.

Kuznetsov, V. I. 1988: New species of tortricid moths of the subfamily Olethreutinae (Lepidoptera, Tortricidae) of the fauna of North Vietnam. - Entomologicheskoe Obozrenie 67: 615-631.

Li, H. H. 2002: The Gelechiidae of China (I) (Lepidoptera: Gelechioidea). - Tianjin: Nankai University Press, 538 pp. [In Chinese.]

Razowski, J. 1989: The genera of Tortricidae (Lepidoptera). Part II: Palaearctic Olethreutinae. — Acta zoologica cracoviensia 32: 107-328.

Zhang, A. H. \& Li, H. H. 2009: First Report and Taxonomic Study of the Genus Metacosma Kuznetsov (Lepidoptera: Tortricidae) in China. — Entomotaxonomia 31: $30-33$. 